\title{
ARTICLE
}

\section{Demarginalizing Standpoint Epistemology}

\author{
Briana Toole \\ Assistant Professor of Philosophy, Claremont McKenna College, CA, USA \\ Email: btoole@cmc.edu
}

(Received 14 September 2019; revised 30 January 2020; accepted 8 February 2020)

\begin{abstract}
Standpoint epistemology, the view that social identity is relevant to knowledge-acquisition, has been consigned to the margins of mainstream philosophy. In part, this is because the principles of standpoint epistemology are taken to be in opposition to those which guide traditional epistemology. One goal of this paper is to tease out the characterization of traditional epistemology that is at odds with standpoint epistemology. The characterization of traditional epistemology that I put forth is one which endorses the thesis of intellectualism, the view that knowledge does not depend on non-epistemic features. I then suggest that two further components - the atomistic view of knowers and aperspectivalism - can be usefully interpreted as supporting features of intellectualism. A further goal of this paper is to show that we ought to resist this characterization of traditional epistemology. I use pragmatic encroachment as a dialectical tool to motivate the denial of intellectualism, and consequently, the denial of both supporting components. I then attempt to show how it is possible to have a view, similar to pragmatic encroachment, that takes social identity, rather than stakes, to be the feature that makes a difference to what a person is in a position to know.
\end{abstract}

Keywords: traditional epistemology; standpoint epistemology; pragmatic encroachment; stakes; intellectualism; social identity; epistemic oppression

\section{Introduction}

Standpoint epistemology has been extensively discussed within academic philosophy and has many fruitful applications. ${ }^{1}$ Yet, much of the expansive work on this topic has been relegated to the margins, serving at best as a footnote to discussions in mainstream epistemology. I attribute this marginalization to two issues. First, there is a concern that standpoint epistemology is open to a number of diverse and sometimes conflicting interpretations. Second, there is a perceived tension between standpoint epistemology and (some characterizations of) traditional epistemology that may motivate a rejection of the former.

Where early feminist scholars conceived of standpoint epistemology as a gendered analog to Marx's analysis of the proletarian standpoint (Hartsock 1983; Harding 1991, 2004), later standpoint epistemologists expanded the scope of their analyses. Rather than examining the role of gender in the acquisition of knowledge, they instead evaluated the extent to which unequal power relations might structure inquiry or

\footnotetext{
${ }^{1}$ See, for instance, Mark Risjord (2010) and Rob Wilson (2017) on applications of standpoint epistemology.

(c) The Author(s) 2020. Published by Cambridge University Press
} 
influence the production of knowledge (Collins 1990; Crasnow 2009; Rolin 2009). Such analyses thus allowed standpoint epistemologists to consider a wide range of potential influences on knowledge - from class and gender to race and sexuality. Still other feminist epistemologists (in particular, feminist empiricists) investigated the influence of gendered (or racialized) norms, expectations, and experiences on the production of knowledge, particularly in scientific inquiry (Longino 1990; Anderson 1995; Kukla and Ruetsche 2002; Rolin 2016).

Despite the richness and value of the standpoint literature, there is a worry, as Kristen Intemann notes, that standpoint epistemology has been interpreted in ways that make it 'either obviously false or trivially true', or in ways that make it 'more plausible, but fairly trivial' (Intemann 2010: 783-4). My first goal here is to give a specific interpretation of standpoint epistemology that is neither obvious nor trivial.

Moreover, some worry that there is a tension between "traditional" epistemology, and standpoint epistemology. Elizabeth Anderson, for instance, writes 'Traditional epistemology finds [the] claims of feminist epistemology to be highly disturbing, if not plainly absurd' (Anderson 1995: 51). Marianne Janack notes this tension, as well, writing, 'Feminist claims ... are often met by incredulity on the part of traditional epistemologists' (Janack 1997: 127).

The source of this tension is up for debate, with some attributing it to the presumed incompatibility between standpoint epistemology and objective inquiry (Harding 1991: esp. Ch. 6; Antony 2006; Kukla 2006), and others locating the tension in the differing conceptions of epistemic agency adopted by each school of thought (Nelson 1990, 1993; Grasswick 2004). ${ }^{2}$ My second goal here is to propose an alternative explanation as to what this tension consists in. I do so by identifying one plausible characterization of traditional epistemology according to which it does stand in a clear tension with standpoint epistemology. This characterization is of traditional epistemology as a form of intellectualism (to use a technical label Jason Stanley has recently popularized). I then investigate the conflict between standpoint epistemology and intellectualism.

Intellectualism is the thesis that knowledge does not depend on non-epistemic features (Stanley 2005: 6). My proposed interpretation of standpoint epistemology will be as a form of the view that knowledge is sensitive to non-epistemic features. It is in this sense that the standpoint thesis is in tension with traditional epistemology, and intellectualism more specifically. Standpoint epistemology thus belongs to a family of views that denies the thesis of intellectualism, including some forms of epistemic relativism (Neta 2007; MacFarlane 2011), as well as pragmatic encroachment (Hawthorne 2004; Stanley 2005).

As I will interpret it, standpoint epistemology takes an epistemic agent's social identity to be a non-epistemic factor that makes a difference to what she is in a position to know. The standpoint thesis, as I have articulated it here, features a number of technical terms that, before I proceed, need to be defined. I define an epistemic agent as any person who has the capacity to acquire knowledge and to share knowledge with others. ${ }^{3}$ The distinction between epistemic and non-epistemic features has been used to frame the debate between intellectualists and their opponents such as Hawthorne (2004), Stanley (2005), Fantl and McGrath (2009), and so on. Neither these authors

\footnotetext{
${ }^{2}$ For arguments that standpoint epistemology is incompatible with objective inquiry, see Haack (1993), as well as Hekman (1997). For challenges to such arguments, see Daston (1992), Anderson (1995), Lloyd (1995), Wylie (2003), Antony (2006), and Kukla (2006), to name but a few.

${ }^{3}$ I define epistemic agent in this way in order to better conceptualize epistemic oppression. As epistemic oppression involves obstructing or excluding some person from the practices of knowledge-production, it has the effect of preventing a person from being a distinctly epistemic agent.
} 
nor I have a precise definition of when a feature is epistemic. ${ }^{4}$ However, paradigm examples give us a strong grasp on the category of epistemic factors: the examples are evidence and justification, truth, belief, reliability - in short, those properties that featured in the post-Gettier trend that characterizes traditional epistemology.

I begin in section 1 by distinguishing the various assumptions that guide the intellectualist position. In undertaking this task, I hope to elucidate the source of the tension between this school of thought and standpoint epistemology. My goal, in doing so, is to offer one way of giving a more concrete specification to the general framework of standpoint epistemology. In order to accomplish this task, I will use as an expository tool a distinct, but related view - pragmatic encroachment. Pragmatic encroachment, like standpoint epistemology, suggests that knowledge is sensitive to non-epistemic features. But where the standpoint epistemologist emphasizes social identity as the non-epistemic feature that makes a difference to what a person is in a position to know, pragmatic encroachment instead focuses on the practical costs associated with being wrong. Using pragmatic encroachment as a spring board, I will show, in sections 2 and 3, how it is possible to have a similar view that takes social identity to be the non-epistemic feature that makes a difference to what a person is in a position to know.

My goal here is not to argue that non-traditional epistemologies should supplant traditional epistemology. Rather, it is to motivate the claim that traditional epistemology should be open to the claims advanced by standpoint epistemologists. My aim, more modestly, is to demonstrate that we need to bring standpoint epistemology out of the margins and into the mainstream.

\section{Exploring the tension}

I take standpoint epistemology to be at odds with those versions of traditional epistemology that treat intellectualism as a core tenet. In defense of this way of characterizing the foil that standpoint epistemologists say their view is in tension with, consider two of the central ideas that leading proponents of standpoint epistemology have attributed to traditional epistemology, theses they aim to criticize. These theses are at the heart of the tension between traditional epistemology and standpoint epistemology. The first, aperspectivalism, is the view that an epistemic agent's justification for some proposition must be accessible to other epistemic agents who are exposed to the same epistemic features of a situation (Kukla 2006). The second, the atomistic view of knowers, is a view which characterizes epistemic agents as generic or interchangeable (Grasswick 2004). Where the intellectualist is committed to both aperspectivalism and the atomistic view of knowers, the standpoint epistemologist (and others in this family) must reject these theses. ${ }^{5}$

On the interpretation that I propose, aperspectivalism means simply that one's evidence for a belief must be such that it is accessible to other agents. So, as an example, if what justifies your belief that the bank will be open this Saturday is that it was open two Saturdays ago, this fact must be information that other epistemic agents can access.

There is a good deal of support for this thesis in the literature. Thomas Kelly, for instance, writes

\footnotetext{
${ }^{4}$ The difficulty of giving a definition was noted long ago by Alvin Goldman (1979: 2).

${ }^{5}$ I only mean here to draw out the account of traditional epistemology that I take to be standpoint epistemology's primary opponent. For a full critique of the atomistic view of knowers, see Nelson (1993) or Grasswick (2004). And, for challenges to aperspectivalism, see Daston (1992) or Kukla (2006).
} 
it is thought central to the concept of evidence that evidence is by its very nature the kind of thing that can generate rational convergence of opinion in virtue of being shared by multiple individuals. This encourages the idea that any genuine piece of evidence can in principle be grasped by multiple individuals; anything which cannot be so grasped is either not genuine evidence or is at best a degenerate species thereof. (Kelly 2016; italics mine)

Support for this thesis is also present in the works of prominent philosophers of science, including Carl Hempel (1952) and Herbert Feigl (1953), as well as Peter Railton (1991), who writes that 'objective inquiry uses procedures that are intersubjective and independent of particular individuals and circumstances - for example ... it makes no essential use of introspective or subjectively privileged evidence in theory assessment' (Railton 1991: 764).

I propose that we interpret the view that evidence must be accessible in the following way: $E$ is evidence that $P$ for $S_{1}$ relative to $S_{2}$ if $E$ is evidence (1) that $S_{2}$ could have, or (2) that $S_{2}$ could rationally infer because (3) $S_{2}$ could know what it's like to have the evidence that $S_{1}$ does. On this interpretation, aperspectivalism allows the intellectualist to rule out, for instance, clairvoyant cases where whatever it is that would count as evidence for the clairvoyant's belief that the president is in New York is not accessible to non-clairvoyants (BonJour 1980). Understanding aperspectivalism in this way allows for the intellectualist to exclude cases like the clairvoyant and to include cases regarding subjective states. For example, I can rationally infer that you are cold based on your behavior and my own experience of what it's like to be cold. In the case of the clairvoyant, I have no experience of what it is like to be clairvoyant, and therefore, I cannot rationally infer what 'evidence' the clairvoyant might have.

Regarding the distinction between epistemic and non-epistemic features, I advance a proposal for how to divide the line between what is accessible and what is not. Epistemic features are those features which are, in a certain natural sense, accessible to everyone. But at least some non-epistemic features, in particular, those associated with social identity, are not so accessible. Aperspectivalism, then, is the view that knowledge is sensitive only to those features which are accessible to all epistemic agents.

However, anti-intellectualists, like pragmatic encroachers, deny aperspectivalism. In the Bank Cases, which I'll discuss further below, the pragmatic encroacher argues that $\mathrm{S}_{1}$ and $\mathrm{S}_{2}$ do not each know $\mathrm{p}$ despite having the same evidence for $\mathrm{p}$. Thus, something other than evidence, something which $S_{1}$ has and $S_{2}$ lacks (or vice versa), something which is accessible to the one and not the other in their determination of $\mathrm{p}$, makes a difference. In the case of pragmatic encroachment, this feature is stakes. The reason to think that certain features, like stakes or facts about one's social identity, are inaccessible, regards the second component of intellectualism, atomism.

As I interpret it, the atomistic view of knowers conceives of knowers as "substitutable", one for the other, such that certain subjective features of $S$ make no difference in whether $\mathrm{S}$ is in a position to know some proposition. A number of other philosophers have explored the role of the atomistic view in our epistemologies, including, for example, Allison Jaggar (1983), Naomi Scheman (1995), and Lorraine Code (1995). On this ideal, Code writes that the atomistic view presupposes that epistemic agents can achieve 'a "view from nowhere" that allows them, through the autonomous exercise of their reason, to transcend particularity and contingency' (Code 1995: 24). Hence, the circumstances and interests of individual knowers are deemed epistemically irrelevant to the acquisition of knowledge.

The atomistic view of knowers is, I believe, best understood in the following spirit: if we, as third-party observers, were evaluating two epistemic agents, $S_{1}$ and $S_{2}$, to 
determine whether they know $\mathrm{p}$, any features particular to that individual would be irrelevant to our determination. Instead, we would ask: given the evidence, does $S_{1}$ (or $S_{2}$ ) know $p$ ? It then wouldn't matter whether we were evaluating $S_{1}$ or $S_{2}$ - looking at the one would give us the answer for the other.

In this respect, the atomistic view of knowers nicely complements aperspectivalism. Lorraine Daston writes that aperspectivalism is 'the ethos of the interchangeable and therefore featureless observer' the goal of which is to '[eliminate] individual (or occasionally group, as in the case of national styles of anthropomorphism) idiosyncrasies' from our epistemic practices (Daston 1992: 599, 609). Thus, taken jointly, these norms work in service of intellectualism by ruling out any role for "idiosyncratic features" (e.g. distorting influences like ideology, bias, prejudice, and other subjective features, like one's preferences, desires, and so on).

I submit that the pragmatic encroacher will also deny atomism. The pragmatic encroacher will argue that we cannot take this "view from nowhere", as whether S knows $\mathrm{p}$ depends on facts relevant to the epistemic agent's position, like whether $\mathrm{S}$ is in a High Stakes case. Thus, something particular to the individual does in fact make a difference in whether an epistemic agent knows $\mathrm{p}$.

It is for this reason that defenders of pragmatic encroachment have argued that intellectualism fails to accurately map onto our intuitions in certain cases. To illustrate, let me turn to the Bank Cases, examples that have been given by Keith DeRose (1992, 2002), and also by Stanley (2005), but that I have modified for my purposes here:

Low Stakes. Hannah and her wife Sarah are driving home on a Friday afternoon. They plan to stop at the bank on the way home to deposit their checks. It is not important that they do so, as they have no impending bills. But as they drive past the bank, they notice that the lines inside are very long, as they often are on Friday afternoons. Realizing that it isn't very important that the paychecks are deposited right away, Hannah says, 'I know the bank will be open tomorrow, since I was there just two weeks ago on Saturday morning. So we can deposit our paychecks tomorrow morning.'

High Stakes. James and his husband Amir are driving home on a Friday afternoon. They plan to stop at the bank on the way home to deposit their paychecks. Noticing the lines are long, James says that he was at the bank two weeks before on a Saturday morning, and it was open. However, they have an impending bill due, and very little in their account, so it is very important that they deposit their paychecks by Saturday. And, as Amir points out, banks do change their hours. James says, 'I guess you're right. I don't know that the bank will be open tomorrow. ${ }^{36}$

Stanley takes it that our intuitive reactions to these cases will be as follows: we will agree that in Low Stakes, Hannah does know that the bank will be open tomorrow, and that in High Stakes, James is right in thinking that he does not know that the bank will be open. We can represent the pragmatic encroacher's argument as follows:

1. Hannah knows the bank is open but James does not know the bank is open.

2. Hannah and James share the same epistemic features.

3. Therefore, some non-epistemic feature makes a difference to what Hannah and James are in a position to know.

\footnotetext{
${ }^{6}$ Stanley stipulates that the bank will be open tomorrow, and that both James and Hannah believe that the bank will be open. But given the practical costs, James does not take himself to know that the bank will be open.
} 
We can see that in Low Stakes and High Stakes, the epistemic agents are exposed to the same epistemic features. Both Hannah and James have evidence that the bank may be open on Saturday, as it was open two weeks ago on a Saturday morning. They are also both aware that banks change their hours, and thus the bank may fail to be open on the Saturday in question. As these are the only features of the epistemic situation available to both agents, then according to intellectualism, this is the only information on which they should base their epistemic judgment. Thus, to refute the argument above, the intellectualist must deny premise one. To do so, she must argue that it is the case either that both Hannah and James know that the bank will be open, or that neither of the two know this.

This strikes the pragmatic encroacher as unintuitive. According to pragmatic encroachment, what best explains our intuition in this case is that a non-epistemic feature - like the stakes associated with being wrong - makes a difference to what the epistemic agents are in a position to know. Thus, if for Hannah the stakes were high, she would not be in a position to know that the bank will be open on Saturday (and the reverse holds for James).

The pragmatic encroacher takes the Bank Cases to motivate a rejection of intellectualism. Primarily, this is because the pragmatic encroacher believes that features particular to an epistemic agent's situation, like the costs associated with being wrong, make a difference to whether she is in a position to know p. The cost of being wrong for Hannah is not a reason available to James (or vice versa). Moreover, the pragmatic encroacher will deny that in this case we can take a "view from nowhere" in assessing whether James or Hannah know p, as doing so would produce unintuitive results.

My standpoint thesis similarly entails the denial of intellectualism. However, where the pragmatic encroacher believes one's practical commitment to a proposition's truth is a feature that is not available to other epistemic agents and which makes a difference to whether she is in a position to know $\mathrm{p}$, the standpoint epistemologist thinks that an epistemic agent's social identity plays this role.

What these views share is the following: neither pragmatic encroachment, nor standpoint epistemology, as I will articulate it, takes the non-epistemic feature in question to affect how confident an epistemic agent ought to be that p. For instance, in the Bank Cases, both Hannah and James ought to be equally confident that p, given the evidence. The difference the non-epistemic feature makes, under pragmatic encroachment, is that it raises the threshold that James must satisfy in order to self-attribute knowledge.

The same is true in the cases that I will offer below to motivate the standpoint thesis. My claim is this: it is reasonable to assume that, in cases like the one I will describe, epistemic agents who occupy different social locations but who have the same set of relevant background beliefs with respect to $\mathrm{p}$, should be equally confident with respect to $\mathrm{p}$. That one is not as equally confident as the other is not rational and is, I will show, best explained by differences in the social location of the epistemic agent.

Where the two views diverge is this: the pragmatic encroacher takes the nonepistemic feature in question (i.e. stakes) to raise the threshold required for knowledge. The standpoint epistemologist, by contrast, takes the non-epistemic feature (i.e. social location) to affect how one reasons with the evidence they have.

Before I proceed to the cases that I take to motivate the standpoint thesis, let me offer the brief caveat that my cases involve a discussion of sexual assault and disbelief of rape testimony. Let me turn to those cases now. 


\section{Clarifying standpoint epistemology}

Standpoint epistemology is the view that an epistemic agent's race or gender can make a difference to what she is in a position to know. Consider the two cases below:

Black Subject. Moira, an African-American resident of Oklahoma City, is watching the local news as they turn to their lead story: 'White Cop Convicted of Serial Rape of Black Women'. The story covers the ongoing case of Daniel Holtzclaw, an Oklahoma City police officer, who is accused of the rape of at least 13 women who, save one, were all African-American women living in a poverty-stricken, predominantly black neighborhood in the northeastern section of the city. The report notes that many of the alleged victims were suspected of prostitution and drug possession, and that many delayed coming forward about the assault. The reporter wonders aloud about the veracity of these women's claims, citing as evidence for her doubt their criminal backgrounds.

Moira says to herself, 'I know those women were sexually assaulted. They took so long to report it because he's a cop and they are poor black women - they thought no one would believe them.'

White Subject. June, a white resident of Oklahoma City, is watching the local news as they turn to their lead story: 'White Cop Convicted of Serial Rape of Black Women'. The story covers the ongoing case of Oklahoma City police officer, Daniel Holtzclaw. Holtzclaw is accused of the rape of at least 13 women who, save one, were all African-American women living in a poverty-stricken, predominantly black neighborhood in the northeastern section of the city. The report notes that many of the alleged victims were suspected of prostitution and drug possession, and that many delayed coming forward about the assault. The reporter wonders aloud about the veracity of these women's claims, citing as evidence for her doubt their criminal backgrounds.

June says to herself, 'Those women have criminal records - they could be lying. I am in no position to know that they were sexually assaulted.'

Daniel Holtzclaw did, in fact, assault these women, and in 2015 he was convicted on 13 counts of sexual assault.

Here, I'm interested in exploring whether there are certain propositions that, given features of their social identity, Moira is in a position to know but that June is not. The propositions that are of particular interest to the standpoint epistemologist are those involving social facts. In this case, Moira knows p: that the women were sexually assaulted. But she knows it because she also knows why they delayed reporting that they were unlikely to be believed.

So knowledge of $\mathrm{p}$ in this case requires knowing social facts, such as that these women delayed reporting, not because they were not in fact assaulted, but because they were unlikely to be believed. There are a number of propositions, like $p$, the knowledge of which requires knowledge of further social facts. The standpoint epistemologist argues that knowing such facts depends on distinctly non-epistemic features. In particular, the standpoint epistemologist will argue that facts about the standpoint an epistemic agent occupies - where one's standpoint is determined by facts about one's social identity will make a difference to what she is in a position to know.

However, the intellectualist will deny that we need to appeal to non-epistemic features to explain that Moira, but not June, knows that the women were sexually assaulted. I briefly consider two explanations the intellectualist might pursue that will allow her to 
maintain a commitment to intellectualism. She can suggest that Moira knows p where June does not either because of (1) differences in their background beliefs or (2) differences in how they evaluate the evidence.

\subsection{Differences in background beliefs}

The intellectualist might first argue that Moira and June's responses can be explained in terms of differences in their background beliefs. Background beliefs may be a part of one's total evidence - thus, if we think that Moira and June have different evidence, this explains why Moira knows p, but that June fails to be in a position to know p.

As Alvin Goldman (2010) notes, it's rare that two people share all their evidence. Although Moira and June have been exposed to the same facts about this case, they have in the past been exposed to different evidence and have had different experiences throughout their lives. These differences are relevant to Moira and June's epistemic assessments of $\mathrm{p}$.

Given her evidence, it's possible that June thinks that the women, because they are poor and have criminal records, have other motivations for coming forward. Or, given her knowledge of police brutality in the African-American community, Moira might have a rational distrust of the police that motivates her to believe the women in this case.

The intellectualist can then maintain a commitment to intellectualism and acknowledge that evidential differences account for why Moira knows, but June fails to know, that $\mathrm{p}$. This is because we can explain Moira's and June's knowledge claims by appealing to the fact that they each had a difference body of evidence for $\mathrm{p}$.

Though I am willing to concede that differences in background beliefs may explain a wide range of cases, there are, I believe, reasons to resist that move here. First, we can stipulate that the background beliefs that are relevant to $\mathrm{p}$ are shared by both Moira and June. It is not unreasonable to think, given the wide availability of information pertaining to police brutality in the Black community, that June has equal access to this information. Still further, the information regarding the professional occupation and criminal status of the women involved is equally available to Moira, as it is information that was made available via the report of the incident.

Moreover, I insist that we must focus only on those background beliefs that are relevant to the belief in question, otherwise such a response has the effect of trivializing the role of evidence. If the mere fact that epistemic agents do not have identical background beliefs can account for why epistemic agents reach different epistemic assessments in a given case, then we ought to expect there to be a large number of cases in which epistemic agents do in fact reach different assessments. My worry, then, is that this response does not provide a non-trivial explanation of the fact that, given the relevant shared evidence, Moira and June differ in their epistemic assessments of p.

However, the intellectualist may insist that there will always be a difference in the relevant evidence that epistemic agents have. I will soon offer additional reasons to think otherwise (section 3.3). My argument will involve showing that while background beliefs may sometimes account for why epistemic agents differ in their epistemic assessments, this does not fully explain the story. Thus, I will show that we must rely on non-epistemic features in order to offer a full explanation.

\subsection{Differences in evaluation of the evidence}

Of course, the intellectualist may grant my assertion that Moira and June share the background beliefs relevant to $\mathrm{p}$, and yet maintain that her view can account for differences in Moira and June's belief. To do so, the intellectualist can argue that Moira's and 
June's responses reflect their different evaluations of the evidence. The evidence in this case consists of the following:

Q: at least 13 women have accused Holtzclaw of sexual assault,

$R$ : many of the alleged victims had criminal backgrounds,

$S$ : many of the alleged victims were poor and black, and

$T$ : the alleged victims delayed coming forward (and in some instances, had to be prompted to do so).

The intellectualist may suggest that June weighs $R$ and $T$ more heavily than she weighs $Q$ and $S$, whereas Moira weighs $Q$ and $S$ more heavily than the other evidence. The intellectualist might argue that it's permissible for June and Moira to weigh the evidence as they choose. And given this, the intellectualist can argue that this explains why Moira and June reach different epistemic assessments of $\mathrm{p}$.

This explanation appeals to a form of permissivism - the view that sometimes there is more than one rational response to a given body of evidence. Miriam Schoenfield, describing the permissivist position she adopts, argues that

the permissivist thinks that what it is reasonable to believe about $p$ needs to be understood relative to some set of epistemic standards. Thus, the reason it is permissible for [Moira] and [June] to differ in their beliefs with regard to $\mathrm{p}$ is that [Moira] and [June] have different sets of standards, which differ regarding whether to believe p, given their body of evidence. (Schoenfield 2013: 200) ${ }^{7}$

According to Thomas Kelly, we can account for the epistemic standards agents adopt by looking at the value they place on either acquiring true beliefs or avoiding false beliefs. Kelly writes

In general, the more value one gives to not believing what's false about some issue, the more it behooves one to be relatively cautious or conservative in forming beliefs about that issue. That is, the more weight one gives to not believing something false, the more it makes sense to hold out until there is a great deal of evidence that $\mathrm{p}$ is true before taking up the belief that $\mathrm{p}$. On the other hand, the more one values not missing out on believing the truth, the more it makes sense to take a somewhat more liberal attitude about how much evidence one expects before taking up the relevant belief. (Kelly 2014: 301)

Thus, the intellectualist can appeal to differential epistemic standards to explain why it is that Moira is in a position to know something that June is not. Namely, the intellectualist can suggest that Moira places a greater value on acquiring true beliefs, whereas June places a greater value on avoiding false beliefs. This in turn explains why each weighs the evidence as she does.

This explanation may appear to satisfy the criteria for intellectualism - it may seem to both meet the condition that knowers are interchangeable, and that their reasons are accessible. On this account, all the epistemic features are the same between Moira and

\footnotetext{
${ }^{7}$ Note that in the original text Schoenfield is discussing epistemic agents in her own case. I have replaced the names she uses with those I give in Black Subject/White Subject.
} 
June. Furthermore, epistemic agents are interchangeable in the sense that the epistemic standards of different rational thinkers are sensitive only to epistemic features. In this sense, it could be argued, it satisfies the atomistic component of intellectualism because it rules out those features that have no bearing on the truth that $\mathrm{p}$. Moreover, the reasons Moira uses in her assessment of $\mathrm{p}$ are accessible to June. The only difference between them is how they choose to weigh those reasons.

Though I find myself sympathetic to the permissivist position, this line of defense is unsatisfying as a defense of intellectualism. I grant that appealing to differences in epistemic standards will explain a great range of cases. But this explanation is incomplete, as the epistemic standards an epistemic agent adopts are partly constituted by non-epistemic features. I submit that in cases like the one described above, there is a tendency among dominantly situated knowers to be overly cautious and to favor avoiding false beliefs. By contrast, there is a tendency among marginally situated knowers to favor acquiring true beliefs. ${ }^{8}$

This tendency of dominantly situated knowers to favor the status quo is, I claim, a non-epistemic factor that is essential to what excludes June from being in a position to know what Moira is in a position to know. This is not a stipulative or technical categorization of the non-epistemic. The natural family of epistemic features, as it figured in traditional post-Gettier epistemology, does not have a place for this difference between dominantly and marginally situated knowers. Thus, a complete explanation of why epistemic agents adopt the epistemic standards that they do will require appealing to non-epistemic facts about the agent.

\section{Appealing to standpoint epistemology}

The standpoint epistemologist will deny that the explanations above can fully account for the differences in Moira's and June's knowledge. Instead, the standpoint epistemologist will argue that a complete explanation will require appealing to some facts about the social identity of each epistemic agent. I will provide a simple sketch of three possible explanations the standpoint epistemologist might offer to account for the role social identity plays in the cases outlined above.

The first explanation I consider suggests that the difference in knowledge can be accounted for in terms of the conceptual resources associated with the social identity of each epistemic agent. I next consider the explanation that which hypothesis an epistemic agent entertains is partly determined by the social identity of that epistemic agent. Both of these explanations have been discussed to some extent in the existing literature, and so my discussion of these proposals will be brief.

However, neither of these explanations fully vindicates the intuition I hope to motivate with Black Subject/White Subject. Thus, I will offer a third explanation, one that has not yet been examined in the standpoint literature. I will argue that an epistemic agent's capacity to embed another's de se mode of presentation as her own depends on facts about her social identity; this in turn will impact what she is in a position to know.

\subsection{Conceptual resources}

The first explanation the standpoint epistemologist can pursue depends on saying the following: one's standpoint allows one to develop conceptual resources in order to

\footnotetext{
${ }^{8}$ See Linda Alcoff $(2007)$ and Charles Mills $(1997,2007)$ for further discussion on the relationship between social identity and epistemic goals.
} 
make sense of the experiences of members of that standpoint. Subsequently, these resources will influence what facts an agent is in a position to know.

This warrants a brief digression on the nature of conceptual resources. Conceptual resources include language, concepts, and their associated criteria. I take it that there is a shared understanding of what is meant by language and concepts. ${ }^{9}$ By criteria, I simply mean the features that might be used to sort objects under concepts. Conceptual resources are tools used by epistemic agents to understand and evaluate their experiences. These resources are not fixed and immutable, but stand open for revision. If we find that our existing resources are inadequate or insufficient, then we are free to revise, reform, and expand those resources as necessary. ${ }^{10}$

The idea that conceptual resources are influenced by social identity, and in turn influence what an epistemic agent is in a position to know, has been advocated by Miranda Fricker (2007), Gaile Pohlhaus (2011), and José Medina (2013), to name but a few. Fricker, for instance, argued that women in the 1970s developed the concept for "sexual harassment" to name their experience of workplace harassment by male colleagues and superiors. At the time, this resource had not yet been widely disseminated to men. As such, women were in a position to know some facts that men were not similarly placed (at the time) to know.

Let me now extend this analysis to the case of Black Subject/White Subject. Since we develop conceptual resources to make sense of our experiences, and the experiences we have may depend on our social identity, then consequently, conceptual resources will differ along lines of social identity. Thus, the standpoint epistemologist can argue that Moira and June possess different conceptual resources given that they occupy different racial identities. These conceptual resources, the standpoint epistemologist can argue, account for why Moira is in a position to know something that June is not. Of course, the intellectualist might ask what conceptual resources are available to Moira that account for why she knows, but June does not, that $p$.

One potential resource is that of hypersexualization. On hypersexualization, Kimberlé Williams Crenshaw writes:

Blacks have long been portrayed as more sexual, more earthy, more gratificationoriented ... Thus Black women are essentially prepackaged as bad women within cultural narratives about good women who can be raped and bad women who cannot. The discrediting of Black women's claims is the consequence of a complex intersection of a gendered sexual system, one that constructs rules appropriate for good and bad women, and a race code that provides images defining the allegedly essential nature of Black women. If these sexual images form even part of the cultural imagery of Black women, then the very representation of a Black female body at least suggests certain narratives that may make Black women's rape either less believable or less important. (Crenshaw 1994: 1271)

As a black woman, Moira occupies a black female standpoint, and consequently, she has access to the resources black women have developed in order to understand the experience of hypersexualization. Thus, given that she has this concept, Moira is in a position to infer the right conclusion from the evidence. That is, she may infer that the women

\footnotetext{
${ }^{9}$ Gaile Pohlhaus (2011) calls these epistemic resources, but I prefer 'conceptual resources' so as to avoid these resources being mistakenly identified as epistemic features.

${ }^{10}$ Consider, as an illustration, how our understanding of 'woman' has changed over time to accommodate trans women. Alternatively, consider how our understanding of 'marriage' has been revised to include homosexual relationships.
} 
delayed reporting because (1) people tend not to believe that black women can be raped and (2) the women thus thought they were unlikely to be believed.

Let me briefly discuss why appealing to conceptual resources is an explanation incompatible with an intellectualist account. First and foremost, the features that allow Moira to know what June does not are distinctly non-epistemic. In this case, what allowed Moira to know $p$ was a feature of her social identity - i.e. her race. Further, consider that in the case of sexual harassment, women were able to know what sexual harassment is, and recognize it when it occurred, because of some feature of their social identity - i.e. gender. However, features of a person's social identity need not change their evidence. So, according to the intellectualist, these are features that should not be relevant to whether an epistemic agent is in a position to know some proposition.

Moreover, we see that Moira and June are not interchangeable in the case described above. Though they are in the same epistemic position, what they are in a position to know differs because of facts about their social identity (and subsequently, facts about the standpoint they occupy). We see, for instance, that Moira knows $p$ because of a stable, but contingent non-epistemic feature about her - namely, her race. And June does not know $p$ precisely because she lacks this feature. Consequently, Moira's grounds for knowing what she does are not available to June. The conceptual resources that Moira has, in virtue of the standpoint she occupies, simply aren't available to June, because June occupies a different standpoint and thus has different resources.

\subsection{Hypotheses}

Another explanation the standpoint epistemologist can explore is that Moira and June entertain different hypotheses to explain why it is that the women in the Holtzclaw case delayed reporting. As Kristen Intemann notes, 'individual experiences and values can influence which hypotheses a researcher is able to generate' (Intemann 2009: 258). And, as Donna Haraway (1978), Carol Gilligan (1987), and Emily Martin (1991) have each noted, cultural narratives about sex and gender can impact which hypothesis scientists propose to interpret a body of data, even when all other evidence is shared. Similarly, the standpoint epistemologist can argue that given their different racial identities, Moira and June might entertain different hypotheses to explain the evidence they possess. $^{11}$

Consider an example. Jack and Jane are independently interested in determining why it is that the logic class they TA for is majority male. Jack surmises that women are under-enrolled because women are uninterested in logic. Jane supposes that the under-enrollment of women is due to the fact that there is a rumor in the department that the lecturer has engaged in inappropriate behavior with female undergraduates in the past.

Now, we can stipulate that Jack and Jane have the same evidence and background beliefs. Let's suppose they have both been informed of the rumors regarding the lecturer and of the view held by some that women are less interested in the mathematical aspects of philosophy. But nevertheless, they entertain different hypotheses as to what best explains the low enrollment of women. Why is this?

For someone who has likely never had to carefully consider which class they are taking so as to avoid serial harassers, it's unlikely that Jack would think that the rumor involving the lecturer would have any impact on enrollment. Jane, on the other

\footnotetext{
${ }^{11}$ By 'entertain' I simply mean that for each, a different hypothesis comes to mind. I do not mean that they are aware of multiple hypotheses and entertain only the one they find most likely.
} 
hand, as a woman in a field where this has long been a problem, might immediately realize the impact this could have on the enrollment of women. Similarly, we might think that Moira, as a black woman, is able to immediately realize why the women in the Holtzclaw case were initially uninterested in filing a report.

In both cases, I think we can explain why Moira and Jane entertain the hypotheses they do by appealing to the standpoint each occupies. We can acknowledge that June and Moira may both occupy a woman's standpoint; but, Moira also occupies a black standpoint, and June does not. Subsequently, Moira may be better placed than is June to consider the role that race may have played in the women's decision not to report. For instance, June, as a white woman, may have never had to consider whether her race influences how others evaluate her. Moira, on the other hand, as a black woman, may have had to consider how her racial identity impacts how seriously she is taken by others.

As should be evident, this is closely related to the explanation regarding conceptual resources. I suggest that the conceptual resources available to an epistemic agent because of her standpoint likely influence which hypotheses she entertains. As I noted previously, Moira, but not June, may possess the concept of hypersexualization, because she has likely suffered this. Consequently, this might inform which hypothesis she considers. By extension, since it's unlikely that June possesses this concept (because as a white woman she may have never had this experience) she might fail to entertain this hypothesis when considering what best explains the women's delayed reporting.

This account can be further developed in terms of the third explanation the standpoint epistemologist might offer: de se knowledge.

\subsection{De se knowledge}

I argue here that de se knowledge can be used as a tool to 'imaginatively grasp' the firstpersonal perspective of another epistemic agent. De se knowledge is personal knowledge that one expresses or grasps using first-personal concepts, e.g. "I", "me", "mine", and so on (Ninan 2010). My argument that de se knowledge can be used to explain why some epistemic agents are in a position to know $p$, where others are not, proceeds in three stages. First, I argue that epistemic agents are able to first-personally grasp the firstpersonal perspective of other agents, such that they can know what those agents know. This involves the epistemic agent possessing an "imaginative capacity" that allows her to "imaginatively grasp" another's first-personal perspective. Second, I suggest that this "imaginative capacity" is more difficult the greater the social distance between epistemic agents. Finally, I conclude by exploring how this explanation applies to the case of Black Subject/White Subject.

Appealing to an argument advanced by Laurie Paul, I argue that epistemic agents use a de se mode of presentation to imaginatively represent the experiences of others. Paul writes that this "imaginative capacity", what she calls "empathy", goes beyond merely allowing yourself to "feel what another feels", or simply "imagining yourself in their shoes". Rather, it involves performing a cognitive act that 'allows you to first personally represent some element of another's experience' (Paul 2016: 198).

Paul claims that when we engage in this imaginative capacity, we need a mode of presentation that allows us to embed another's mode of presentation into our own, such that we first-personally grasp that person's first-personal perspective. To do so, we must engage in a subjective mode of presentation, what Paul calls the "de se mode of presentation". This mode of presentation allows us to subjectively represent some element of that person's experience and to draw on what is learned. 
This is to go beyond merely imagining what it must be like to have some experience. Rather, it requires that we imagine what it is like to be that person having the experience.

Returning to the cases above, this means that June cannot simply imagine what it might have been like to be sexually assaulted by a cop. Instead, she must imagine what it must have been like, as those women, to have been assaulted by a cop. However, I submit that this is more difficult for June, than for Moira, since there is greater social distance between June and the alleged victims than between Moira and the alleged victims.

Social distance describes the distance between groups of society. To illustrate, June and Moira are not socially distant in terms of gender, but are socially distant in terms of race. One charge that has been levied against using empathy as tool of moral reasoning, by Jesse Prinz (2011) and Paul Bloom (2016), among others, is that our capacity to empathize with another person varies as a function of social distance. Paul herself notes this, writing that 'to have the capacity for empathy seems to require a certain amount of shared experience' (Paul 2016: 199).

Extending this, I suggest that the greater the social distance between two people, the more difficult it will be for one to engage in the de se mode of presentation in order to represent the other's experience. In turn, the less socially distant two people are, the more easily they will find it to "imaginatively grasp" the other's perspective. As Paul also writes, 'the empathetic task involves grasping some relevant feature of another person's first personal perspective' (Paul 2016: 199). If the epistemic agent is unable to imaginatively grasp the relevant feature, then I suggest she will also be unable to accurately represent the other person's first personal perspective.

The intellectualist might object that given the pervasiveness of bias in applications of empathy, we ought to rule it out as an epistemic tool. But it is precisely for this reason that I think empathy is epistemically significant. Because we are better able to "imaginatively grasp" the perspectives of those who are most like us, this explains why some epistemic agents are better placed than others to know certain propositions. Others have noted that in moral judgments, empathy plays a crucial epistemic role in determining when (and whether) moral (dis)approbation is warranted. It is not implausible to suggest that it plays a significant role in epistemic evaluations, as well.

However, empathy should not be considered a distinctively epistemic feature. As such, the intellectualist cannot account for its role in epistemic evaluations. Consider that empathy is neither evidence, nor is it a background belief. It is simply a capacity. As Paul writes, when one engages the de se mode of presentation, she does not learn new information so much as she gains a new ability. ${ }^{12}$

Extending this argument to the cases above, it's plausible that June can imaginatively conceive of what it must be like to be a woman at the center of the Holtzclaw case. But as she is not black, and has no lived experience of being black, I argue it will be more difficult to conceive of what it must be like to be a black woman at the center of the Holtzclaw case. Furthermore, while June, when she imagines herself as one of these women, might think she is representing their experience, her representation likely

\footnotetext{
${ }^{12}$ The traditional epistemologist might object, here, that differential capacities allow for differences in evidence. For instance, those with functioning visual perceptual systems are in a position to gather more evidence than those with faulty visual perceptual systems. However, this is not analogous to Black Subject/White Subject. We must still provide an explanation that accounts for why social identity makes a difference in one's ability to acquire or utilize some capacity, as it does in the case I have outlined here.
} 
fails to build in the blackness of the experiencer. This is especially likely given that "whiteness" is regarded as racially neutral, which means that she may fail to see the salience of race in her own experiences, and thus fail to build a racial dimension into such representations (Tatum 1997: esp. Ch 6). Consequently, I suggest it will be more difficult for June (than for Moira) to imaginatively grasp why the women may have acted as they did.

Moira, as a black woman herself, will have little trouble "building in blackness" into her representation. Given her lived experiences as a black woman, Moira can more easily imagine herself as the victim in the Holtzclaw case, and from that perspective, she can infer, and come to know, the most likely explanation for why the women delayed reporting.

This explanation may work in tandem with the two previously considered to explain why Moira, but not June, is in a position to know that p. I suggest that which hypothesis an epistemic agent entertains will depend on her conceptual resources, and which conceptual resources she has will depend on how capable she is of taking on the perspective in question (where this will depend on the social identity of the agent and of the perspective she is trying to imaginatively grasp).

When Moira first-personally grasps the first-personal perspective of Holtzclaw's victims, she is able to know those women and their experiences. Furthermore, as a black woman herself, she is able to utilize the conceptual resources developed by black women to understand their shared social experiences. It is because Moira is black and she can, more effectively than could June, engage in this perspectivetaking, that she is able to imagine the kinds of experiences black women are likely to suffer. Consequently, she is better placed to develop the conceptual resources necessary to understand these experiences, and then arrive at the hypothesis that she does. As a black woman, Moira can know (where June cannot) that other black women might not report for fear of being believed. She can know this because she can know why she might not have reported, had she been the victim. Consequently, she can know that in the Holtzclaw case, the victims delayed reporting for the same reason.

It is worth asking if this appeal to empathy will work in other epistemic contexts, particularly outside of the social sciences. ${ }^{13}$ Though I cannot say a great deal about this here, I believe that empathy is an invaluable tool in inquiry, even in the 'hard' sciences. It is not implausible that the data researchers collect, the research agendas they set, and the methods they undertake, could be improved if they empathized more with the populations they study. Still further, if different cognitive and intellectual abilities, skills, and interests allow for the discovery, interpretation, and explanation of different data in such a way that improves our scientific enterprises, then it is not implausible to think empathy plays a similar such role.

Consider now a few illustrative examples where empathy might play just such a role. In particular, let's start with research that is taken to provide support for biological determinism. Intemann (2009) evaluates one study in particular which was used to support the view that women are worse at visual-spatial reasoning than are men. The experiment, she notes, asked women participants to sit alone in a dark room with an unfamiliar, male researcher. As she writes:

White middle-class and upper-class researchers in the 1960s were unlikely to have had the kinds of experiences that would make them aware of what it was like to be

\footnotetext{
${ }^{13}$ Thank you to an anonymous referee at the Journal of Philosophy for drawing my attention to this point.
} 
nervous of being in a dark room with a strange man or to be discouraged or penalized for being assertive or demanding. (Intemann 2009: 258)

I suggest that the male researchers' inability to empathize with their female test subjects produced distorted data. Had they empathized more with their subjects, they might have considered alternative explanations for the female test subjects' poor performance on the visual-spatial tests they were assigned.

Moreover, considering alternative perspectives some populations have to certain objects of inquiry might also shape, and ultimately enhance, our research programs. Consider, for instance, the contributions of Indigenous peoples to knowledge of firespreading among animals. As researchers Bonta et al. (2017) note, it is widely known to Indigenous people in Australia that, to aid in food collection, "firehawks" will intentionally spread fire by transporting burning sticks. ${ }^{14}$ This fact is represented in their cultural ceremonies and their creation myths. However, Western science is only now discovering this fact long known to Native peoples. Prior to Western investigation into this phenomenon, this thesis was met with skepticism.

Generally speaking, Western scientific practices tend to be at odds with traditional Native American practices of knowledge production (Hester and Cheney 2001). In part, this is because these different social and cultural groups employ different research paradigms. Where, for instance, traditional epistemology is individualistic and directs us to reject paradigms that are not value-neutral and objective, traditional Native knowledge is often communal, anecdotal, imprecise, and value-laden (Gill 1999; Hester and Cheney 2001). If, rather than being dismissive, we empathized more with Native populations and their attitudes towards plants, animals, and so on - and in so doing came to have a better appreciation of why they employ the paradigms that they do - we might generate new data, offer better interpretations of existing data, or come to understand phenomena that were obscure to us before. ${ }^{15}$

\section{Concluding remarks}

The task of the standpoint epistemologist is to provide a theoretical framework that explains why features of our social identity make a difference to what an epistemic agent is in a position to know. I've gestured at a few possible responses the standpoint epistemologist might offer here. I have not, however, specified what a standpoint consists in, nor have I considered how a standpoint arises. Further work may examine how standpoints, in particular dominant and marginal social positions, are largely constituted by these features that, though non-epistemic, make a critical difference to knowledge. My task here has been to demonstrate what is at the heart of the tension between standpoint epistemology and one characterization of traditional epistemology, and to motivate the standpoint epistemologist's argument.

Traditional epistemology, as I have interpreted it, operates from the assumption of an idealized rational framework and conceives of knowers in 'abstraction from relations of social power' (Fricker 2007: 3). This account thus obscures questions that arise when we conceive of the knower as socially situated. Those traditional epistemologists committed to intellectualism may either concede that non-epistemic factors do in fact make a difference to knowledge (thereby rejecting intellectualism), or argue that features of our social identity, inasmuch as they do make a difference to knowledge, count as

\footnotetext{
${ }^{14}$ 'Firehawks' is a term for birds, particularly kites and falcons, that engage in fire-spreading behavior.

${ }^{15}$ This is especially true as it applies to ecology, climatology, biology, and related fields. See, for instance, Thorpe (2001), Laidler (2006), and Deur et al. (2015).
} 
epistemic features. In this way traditional epistemology can be open to the lessons standpoint epistemology has to offer. ${ }^{16}$

\section{References}

Alcoff L.M. (2007). 'Epistemologies of Ignorance: Three Types.' In S. Sullivan and N. Tuana (eds), Race and Epistemologies of Ignorance, pp. 39-58. New York, NY: State University of New York Press.

Anderson E. (1995). 'Feminist Epistemology: An Interpretation and a Defense.' Hypatia 10(3), 50-84.

Antony L. (2006). 'The Socialization of Epistemology.' In R.E. Goodin and C. Tilly (eds), The Oxford Handbook of Contextual Political Analysis, pp. 58-77. Oxford: Oxford University Press.

Bloom P. (2016). Against Empathy: The Case for Rational Compassion. New York, NY: Harper Collins.

BonJour L. (1980). 'Externalist Theories of Empirical Knowledge.' Midwest Studies in Philosophy 5, 53-73.

Bonta M., Gosford R., Eussen D., Ferguson N., Loveless E. and Witwer M. (2017). 'Intentional Fire-Spreading by 'Firehawk' Raptors in Northern Australia.' Journal of Ethnobiology 37(4), 700-18.

Code L. (1995). Rhetorical Spaces: Essays on Gendered Locations. London: Routledge.

Collins P. (1990). Black Feminist Thought: Knowledge, Consciousness, and the Politics of Empowerment. London: Routledge.

Crasnow S. (2009). 'Is Standpoint Theory a Resource for Feminist Epistemology? An Introduction.' Hypatia 24(4), 189-92.

Crenshaw K.W. (1994). 'The Marginalization of Sexual Violence against Black Women.' NCASA Journal 2(1), 1-15.

Daston L. (1992). 'Objectivity and the Escape from Perspective.' Social Studies of Science 22(4), 597-618.

DeRose K. (1992). 'Contextualism and Knowledge Attributions.' Philosophy and Phenomenological Research 52(4), 913-29.

DeRose K. (2002). 'Assertion, Knowledge, and Context.' Philosophical Review 11(2), 167-203.

Deur D., Dick A., Recalma-Clutesi K. and Turner N.J. (2015). 'Kwakwaka'wakw 'Clam Gardens'.' Human Ecology 43(2), 201-12.

Fantl J. and McGrath M. (2009). Knowledge in an Uncertain World. Oxford: Oxford University Press.

Feigl H. (1953). 'The Scientific Outlook: Naturalism and Humanism.' In H. Feigl and M. Brodbeck (eds), Readings in the Philosophy of Science: Naturalism and Humanism, pp. 8-18. New York, NY: Appleton-Century-Crofts.

Fricker M. (2007). Epistemic Injustice: Power and the Ethics of Knowing. Oxford: Oxford University Press.

Gill J. (1999). 'Knowledge, Power, and Freedom: Native American and Western Epistemological Paradigms.' Philosophy Today 43(4), 423-38.

Gilligan C. (1987). 'Moral Orientation and Moral Development.' In E.F. Kittay and D.T. Meyers (eds), Women and Moral Theory, pp. 19-36. Lanham, MD: Rowman and Littlefield.

Goldman A.I. (1979). 'What is Justified Belief?' In G. Pappas (ed.), Justification and Knowledge, pp. 1-23. Dordrecht: Reidel.

Goldman A.I. (2010). 'Epistemic Relativism and Reasonable Disagreement.' In R. Feldman and T. Warfield (eds), Disagreement, pp. 187-215. Oxford: Oxford University Press.

Grasswick H.E. (2004). 'Individuals-in-Communities: The Search for a Feminist Model of Epistemic Subjects.' Hypatia 19(3), 85-120.

Haack S. (1993). 'Epistemological Reflections of an Old Feminism.' Reason Papers 18, 31-43.

Haraway D. (1978). 'Animal Sociology and a Natural Economy of the Body Politic, Pts. 1 and 2.' Primate Visions: Gender, Race, and Nature in the World of Modern Science. London: Routledge.

Harding S. (1991). Whose Science? Whose Knowledge? Thinking from Women's Lives. Milton Keynes: Open University Press.

Harding S. (2004). 'A Socially Relevant Philosophy of Science? Resources from Standpoint Theory's Controversiality.' Hypatia 19(1), 25-47.

Hartsock N. (1983). "The Feminist Standpoint: Developing the Ground for a Specifically Feminist Historical Materialism.' In S. Harding and M.B. Hintikka (eds), Discovering Reality: Feminist

\footnotetext{
${ }^{16}$ I owe a large debt of gratitude to audiences at MIT, Princeton, and NYU for their thoughtful questions and objections. Thanks as well to Sinan Dogramaci, Dustin Locke, Miriam Schoenfield, Louise Antony, and Sally Haslanger for many helpful comments and discussions.
} 
Perspectives on Epistemology, Metaphysics, Methodology, and Philosophy of Science, pp. 283-310. Dordrecht: Reidel.

Hawthorne J. (2004). Knowledge and Lotteries. Oxford: Oxford University Press.

Hempel C.G. (1952). Fundamentals of Concept Formation in Empirical Science. Chicago, IL: University of Chicago Press.

Hekman S. (1997). 'Truth and Method: Feminist Standpoint Theory Revisited.' Signs 22(2), 341-65.

Hester L. and Cheney J. (2001). 'Truth and Native American Epistemology.' Social Epistemology 15(4), 319-34.

Intemann K. (2009). 'Why Diversity Matters: Understanding and Applying the Diversity Component of the National Science Foundation's Broader Impacts Criterion.' Social Epistemology 23(3-4), 249-66.

Intemann K. (2010). '25 Years of Feminist Empiricism and Standpoint Theory: Where Are We Now?' Hypatia 25, 778-96.

Jaggar A.M. (1983). Feminist Politics and Human Nature. Lanham, MD: Rowman and Littlefield.

Janack M. (1997). 'Standpoint Epistemology Without the 'Standpoint'? An Examination of Epistemic Privilege and Epistemic Authority.' Hypatia 12(2), 125-39.

Kelly T. (2014). 'Evidence Can Be Permissive.' In M. Steup and E. Sosa (eds), Contemporary Debates in Epistemology, pp. 298-311. Oxford: Wiley Blackwell.

Kelly T. (2016). 'Evidence.' In E.N Zalta (ed.), The Stanford Encyclopedia of Philosophy, https://plato. stanford.edu/archives/win2016/entries/evidence/.

Kukla R. (2006). 'Objectivity and Perspective in Empirical Knowledge.' Episteme 3(1), 80-95.

Kukla R. and Ruetsche L. (2002). 'Contingent Natures and Virtuous Knowers: Could Epistemology be 'Gendered'?' Canadian Journal of Philosophy 32(3), 389-418.

Laidler G. (2006). 'Inuit and Scientific Perspectives on the Relationship Between Sea Ice and Climate Change: The Ideal Complement?' Climatic Change 78, 407-44.

Lloyd E. (1995). 'Objectivity and the Double Standard for Feminist Epistemologies.' Synthese 104(3), 351-81.

Longino H. 1990. Science as Social Knowledge. Princeton, NJ: Princeton University Press.

MacFarlane J. (2011). 'Relativism and Knowledge Attributions.' In S. Bernecker and D. Pritchard (eds), The Routledge Companion to Epistemology, pp. 536-44. London: Routledge.

Martin E. (1991). 'The Egg and the Sperm: How Science Has Constructed a Romance Based on Stereotypical Male-Female Roles.' Signs 16(3), 485-501.

Medina J. (2013). The Epistemology of Resistance: Gender and Racial Oppression, Epistemic Injustice, and Resistant Imaginations. Oxford: Oxford University Press.

Mills C.W. (1997). The Racial Contract. Ithaca, NY: Cornell University Press.

Mills C.W. (2007). 'White Ignorance.' In S. Sullivan and N. Tuana (eds), Race and Epistemologies of Ignorance, pp. 11-38. New York, NY: State University of New York Press.

Neta R. (2007). 'In Defense of Epistemic Relativism.' Episteme 4(1), 30-48.

Nelson L.H. (1990). Who Knows: From Quine to a Feminist Empiricism. Philadelphia, PA: Temple University Press.

Nelson L.H. (1993). 'Epistemological Communities.' In L. Alcoff and E. Potter (eds), Feminist Epistemologies, pp. 121-59. New York, NY: Routledge.

Ninan D. (2010). 'De Se Attitudes: Ascription and Communication.' Philosophy Compass 5(7), 551-67.

Paul L.A. (2016). 'First Personal Modes of Presentation and the Structure of Empathy.' Inquiry 60(3), 189207.

Pohlhaus G. (2011). 'Relational Knowing and Epistemic Injustice: Toward a Theory of Willful Hermeneutical Ignorance.' Hypatia 27(4), 715-35.

Prinz J. (2011). 'Against Empathy.' Southern Journal of Philosophy 49, 214-233.

Railton P. (1991). 'Marx and the Objectivity of Science.' In R. Boyd, P. Gasper and J.D. Trout (eds), The Philosophy of Science, pp. 763-73. Cambridge, MA: MIT Press.

Risjord M. (2010). Nursing Knowledge: Science, Practice, and Philosophy. Oxford: Wiley-Blackwell.

Rolin K. (2009). 'Standpoint Theory as a Methodology for the Study of Power Relations.' Hypatia 24(4), $218-26$.

Rolin K. (2016). 'Values, Standpoints, and Scientific/Intellectual Movements.' Studies in History and Philosophy of Science 56, 11-19.

Scheman N. (1995). 'Symposium: Feminist Epistemology.' Metaphilosophy 26(3), 177-90.

Schoenfield M. (2013). 'Permission to Believe: Why Permissivism Is True and What It Tells Us About Irrelevant Influences on Belief.' Noûs 48(2), 193-218.

Stanley J. (2005). Knowledge and Practical Interests. Oxford: Oxford University Press. 
Tatum B.D. (1997). 'The Development of White Identity.' In B.D. Tatum (ed.), Why Are All the Black Kids Sitting Together in the Cafeteria?, pp. 93-113. New York, NY: Basic Books.

Thorpe N. (2001). 'Climate and Caribou: Inuit Knowledge of the Impacts of Climate Change.' In H. Hunting (ed.), Arctic Flora \& Fauna: Status and Conservation, p. 101. Helsinki: CAFF (Conservation of Arctic Flora and Fauna).

Wilson R. (2017). The Eugenics Mind Project. Cambridge, MA: MIT Press.

Wylie A. (2003). 'Why Standpoint Matters.' In R. Figueroa and S.G. Harding (eds), Science and Other Cultures: Diversity in the Philosophy of Science and Technology, pp. 26-48. London: Routledge.

Briana Toole received her PhD from the University of Texas at Austin in 2018. Her research sits at the intersection of epistemology, feminist theory, and philosophy of race, and focuses on the role of social identity in knowledge acquisition. She is the founder of philosophy outreach program Corrupt the Youth.

Cite this article: Toole B (2020). Demarginalizing Standpoint Epistemology. Episteme 1-19. https:// doi.org/10.1017/epi.2020.8 